\title{
Envelhecimento populacional e o impacto da Previdência Social e do Benefício de Prestação Continuada nos municípios do Conselho Regional de Desenvolvimento do Litoral (RS) ${ }^{1}$
}

\author{
Rossandra Oliveira Maciel de Bitencourt ${ }^{2}$ \\ Fabiano Abranches Silva Dalto ${ }^{3}$
}

\begin{abstract}
Resumo: Este trabalho consiste em analisar o processo de envelhecimento populacional no Conselho Regional de Desenvolvimento (Corede) do Litoral/RS atentando para o desempenho da Previdência Social e do Benefício de Prestação Continuada (BPC) nos municípios da região. Foi realizado um levantamento de dados junto ao Instituto Brasileiro de Geografia e Estatística (IBGE), ao Programa das Nações Unidas para o Desenvolvimento (PNUD), à Secretaria de Previdência Social, ao Ministério do Desenvolvimento Social (MDS) e ao Sistema de Informações Contábeis e Fiscais do Setor Público Brasileiro (Sinconfi) para a análise quantitativa. No período de 2000-2010, constatou-se que a região do Corede teve o maior aumento populacional no estado. Apenas a população acima de 60 anos aumentou 75\%, superando as médias estadual e nacional. Explica-se esta dinâmica por dois fatores: aumento da população idosa nos balneários proveniente de pessoas que residiam na região metropolitana do estado, em busca de um lugar que propicie lazer e maior qualidade de vida; e, por outro lado, nos municípios rurais verifica-se os fenômenos do êxodo juvenil, da masculinização e do envelhecimento do campo. Em suma, este trabalho revela que a Previdência Social e o BPC asseguram aos idosos residentes no Corede Litoral a garantia de uma fonte regular de renda que lhes confere o mínimo de segurança e dignidade. Seja nos balneários, no campo ou nos municípios economicamente mais vulneráveis, a transferência destes recursos atua contribuindo significativamente para o desenvolvimento socioeconômico da região.
\end{abstract}

Palavras-chave: Envelhecimento Populacional. Benefício de Prestação Continuada. Previdência Social. Corede Litoral.

Abstract: This work consists of analyzing the process of the ageing of the population in the Regional Development Council (Corede) of Litoral / RS, paying attention to the performance of Social Security and the Continuous Benefits of Provision in the municipalities of the region. The methodology used was a survey of data from the Brazilian Institute of Geography and Statistics (IBGE), the United Nations Development Program (UNDP), the Department of Social Security, the Ministry of Social Development (MDS) and the Accounting and Tax Information System of the Brazilian Public Sector (Sinconfi); the analysis approach was quantitative. In the period of 2000-2010, it was verified that this was the region of the state with greatest population increase. In relation to the population above 60 years, this increase was $75 \%$, surpassing the state and the national averages. On one hand, there is an increase in the elderly population in the balnearies of the region coming from people who lived in the metropolitan region of the state, who, after retirement, looj for a quiet place that provides leisure and a better quality of life. On the other hand, in the rural municipalities it is seen the phenomena of the youth exodus, the masculinization and the aging in the countryside. In sum, this study reveals

\footnotetext{
${ }^{1}$ A presente pesquisa foi realizada com auxílio da Coordenação de Aperfeiçoamento de Pessoal de Nível Superior (CAPES).

2 Doutoranda em Políticas Públicas na Universidade Federal do Paraná. rossandra.maciel@yahoo.com.br

${ }^{3}$ Doutor em Economia Institucional. Professor do Departamento de Economia e do Programa de Pós-Graduação em Políticas Públicas da Universidade Federal do Paraná. fabdalto@gmail.com
} 
that Social Security and the Continuous Benefit of Provision ensure the elderly residents in Corede Litoral the guarantee of a regular source of income that gives them a minimum of security and dignity. Whether in the balnearies, in the countryside or in the economically most vulnerable municipalities, the transfer of these resources, as neutral as it may be, acts significantly contributing to the socioeconomic development of the region.

Keywords: Ageing of the Population. Continuous Benefits of Provision. Social Security. Corede Litoral.

\section{Introdução}

Segundo dados do Instituto Brasileiro de Geografia e Estatística (IBGE), a população residente no Brasil com idade superior a 60 anos aumentou 42\% no período de 2000 a 2010 . Tal aumento tem exigido dos formuladores de políticas públicas um novo olhar frente a esta população. Dentre os avanços conquistados pela geração idosa no Brasil, destaca-se a Constituição Federal de 1988 que ampliou direitos civis e sociais. Entre estes está a garantia de uma renda para a população idosa, por meio de benefícios contributivos (previdenciários), ou não contributivos. O resultado foi o aumento da proporção de idosos que recebem benefícios e, consequentemente, o aumento da importância deste tipo de provento na renda total do idoso (CAMARANO, KANSO e FERNANDES, 2016).

Entende-se que no ideário de provisão social está a origem da Seguridade Social no Brasil quando esta foi instituída pela Constituição de 1988. Segundo o Art. 194, compete ao Poder Público organizar a Seguridade Social com base nos objetivos da universalidade da cobertura e do atendimento, da uniformidade e equivalência dos benefícios e serviços, da seletividade e distributividade na prestação dos benefícios e serviços, da irredutibilidade do valor dos benefícios, da equidade na forma do custeio, da diversidade da base do financiamento, e do caráter democrático e descentralizado da administração. Portanto, a amplitude destes objetivos expressa o mesmo entendimento da Organização Internacional do Trabalho (OIT), de que:

\footnotetext{
as políticas de proteção social compreendem a garantia de condições de trabalho decente, como o respeito à legislação trabalhista e aos princípios de saúde e segurança no trabalho, bem como regimes de seguridade social e um conjunto de políticas para proteger grupos especialmente vulneráveis da população trabalhadora (OIT 2012, p.6).
} 
No cenário internacional a geração idosa também ganhou espaço através da I Assembleia Mundial sobre Envelhecimento que ocorreu em 1982 em Viena; e da II Assembleia Mundial sobre Envelhecimento que ocorreu no ano de 2002 em Madrid. Nesta mais recente, frisou-se que o envelhecimento ao invés de ser percebido como um problema é antes uma conquista para a sociedade, o que constitui a razão de se promover uma visão positiva da geração idosa. Na última assembleia destacou-se ainda que o envelhecimento deve ocupar um lugar fundamental em todas as prioridades no domínio do desenvolvimento, garantindo sua participação ativa na vida econômica, social, cultural e política.

Neste contexto, busca-se investigar o processo de envelhecimento populacional no Conselho Regional de Desenvolvimento (Corede) do Litoral/RS atentando para o impacto da Previdência Social e do Benefício de Prestação nos municípios da região. Segundo o último censo do IBGE, o estado do Rio Grande do Sul possui 497 municípios que estão divididos em 28 Conselhos Regionais de Desenvolvimento (Coredes). A escolha do Corede Litoral para presente pesquisa deriva do aumento considerável de sua população acima de 60 anos no período de 2000 a 2010 cujo dado foi de $75 \%$, aumento superior a todos os demais Coredes, e à média nacional, que foi de $42 \%$ para o referido período.

No tocante a metodologia, realizou-se um levantamento de dados abrangendo variáveis demográficas dos municípios que contemplam a região. Tais informações foram coletadas através do Censo do IBGE e do Programa das Nações Unidas para o Desenvolvimento (PNUD). Outro levantamento paralelo foi feito junto à Secretaria de Previdência Social que pertence atualmente ao Ministério da Fazenda, cujos anuários e bancos estatísticos forneceram um mapeamento do valor e da quantidade de benefícios emitidos para cada município da região no ano de 2017. As informações referentes ao Benefício de Prestação Continuada para o mesmo ano foram obtidas através da plataforma disponibilizada pelo Ministério do Desenvolvimento Social (MDS). E por fim, foram analisadas neste mesmo período as receitas orçamentárias de cada município fornecidas pelo Sistema de Informações Contábeis e Fiscais do Setor Público Brasileiro (Sinconfi). A abordagem de análise foi quantitativa. 
Este estudo perpassa um debate central ao mensurar o impacto do Estado como provedor de direitos sociais. Para tanto, a partir de Skocpol (1985) e Hodgson (2006) assumese na presente pesquisa o Estado como uma estrutura institucional que, em constante transformação, é capaz de influenciar de diferentes formas a sociedade bem como a vida dos indivíduos.

O artigo está dividido em cinco partes. Após esta breve introdução, a seguir abordase algumas considerações sobre o processo de envelhecimento no Brasil bem como o papel da Previdência Social e do Benefício de Prestação Continuada enquanto políticas sociais. $\mathrm{Na}$ sequência estão os resultados desta pesquisa, e por fim encontram-se as considerações finais acerca do que foi observado.

\section{Considerações sobre o processo de envelhecimento no Brasil}

Há um aumento considerável na proporção de idosos com relação à população total em praticamente todos os lugares do mundo. Segundo a ONU (2015) no período entre 2015 e 2030, o número de pessoas no mundo com 60 anos ou mais está projetado para crescer em 56\%, de 901 milhões para 1 bilhão e 400 milhões. Contudo, embora o envelhecimento da população seja um fenômeno mundial, o processo de envelhecimento é mais avançado em algumas regiões do que em outras, tendo começado há mais de um século atrás em países que se desenvolveram mais cedo. Já nos países em desenvolvimento, considera-se o processo de envelhecimento algo recente, devido ao declínio das taxas de fecundidade que se deu mais tardiamente.

Consequentemente, hoje os países em desenvolvimento têm de se adaptar mais rapidamente ao envelhecimento da população a níveis mais baixos de renda nacional em comparação com a experiência de países que se desenvolveram mais cedo. A ONU (2015) também destaca que o número de pessoas idosas nas regiões menos desenvolvidas aumentou 60\% de 2000 a 2015. E prevê-se um crescimento de $71 \%$ entre 2015 e 2030.

Em meio a este aumento da população idosa no Brasil, Camarano et al. (2004) revelam que o envelhecimento da população não se restringe apenas ao contingente de 
pessoas que alcança os 60 anos. Mas destacam que há um aumento na proporção da população "mais idosa", a de 80 anos e mais, alterando a composição etária dentro do próprio grupo. Logo, é possível afirmar que a população considerada idosa também está envelhecendo.

Neste aspecto a ONU (2015) salienta que, globalmente, o número de pessoas com 80 anos ou mais está crescendo ainda mais rápido do que o número de pessoas idosas em geral. Já no que tange à feminização do envelhecimento, em 2015 as mulheres representavam $54 \%$ da população global de 60 anos ou mais e $61 \%$ das pessoas acima de 80 anos.

É este movimento de envelhecimento que leva ao estreitamento da base e alargamento do topo da pirâmide demográfica. Camarano et al. (2004) afirmam que tais alterações levam a uma heterogeneidade do segmento populacional que extrapola a da composição etária - dadas as diferentes trajetórias de vida experimentadas pelos idosos. Acrescenta-se ainda a questão de que um mesmo grupo etário abrange um intervalo de aproximadamente 30 anos: com pessoas na faixa de 60 anos, que, pelos avanços tecnológicos da medicina, podem estar em pleno vigor físico e mental; bem como pessoas na faixa de 90 anos, que devem se encontrar em situações de maior vulnerabilidade.

Em suma, conforme destacam Camarano et al. (2004), o processo de envelhecimento que se intensifica resulta do "sucesso" de políticas econômicas e sociais que promoveram uma melhoria das condições de vida, em geral, e de saúde, em particular. No caso da população brasileira, tem-se observado desde a segunda metade dos anos 1950, embora de forma desigual, maior acesso a serviços médicos preventivos e curativos, a tecnologia médica avançada, a água tratada, a esgoto e saneamento, a escolaridade dentre outros.

Portanto infere-se que o século XXI testemunhará um envelhecimento mais rápido do que o ocorrido no século passado. Conforme destaca Motta (1999), os velhos estão socialmente mais visíveis no cotidiano e no espaço público. Sobretudo, como resposta existencial geracional à própria dinâmica da sociedade contemporânea. Segundo Siqueira et.al (2002), este processo de envelhecimento demográfico, que repercute nas diferentes esferas da estrutura social, denota demandas específicas que se adequem às condições de 
vida dos idosos. Logo, o desafio é garantir que os indivíduos possam envelhecer com segurança e dignidade, mantendo sua participação ativa na sociedade, e que as relações entre as gerações sejam constantemente estimuladas.

Após estas breves considerações sobre o processo de envelhecimento no Brasil, a seguir discute-se o papel da Previdência Social e do Benefício de Prestação Continuada enquanto políticas sociais.

\section{Previdência Social e Benefício de Prestação Continuada enquanto Políticas Sociais}

De modo geral, a Previdência Social e o Benefício de Prestação Continuada pertencem ao campo da Seguridade Social que, em conjunto, traduzem-se em políticas sociais. Castro (2011) embora concorde que o termo Política Social possa ser interpretado de várias formas e que para defini-lo há uma série de limitações e dificuldades, busca caracterizá-lo como sendo um conjunto de ações e programas do Estado. Tal conjunto é responsável por promover a oferta de bens, serviços e transferências de renda, com a finalidade de suprir as necessidades e os direitos sociais, sobretudo no que se refere à redução da pobreza e da desigualdade.

De acordo com Pereira (2011), é mediante a política social que os direitos sociais se concretizam e as necessidades humanas são atendidas na perspectiva da cidadania ampliada:

\footnotetext{
A política social se apresenta como um conceito complexo que não condiz com a ideia pragmática de mera provisão ou alocação de decisões tomadas pelo Estado e aplicada verticalmente na sociedade. [...] ela é identificada como uma política de ação, que tem perfil, funções e objetivos próprios e produz impactos no contexto em que atua (PEREIRA, 2011, p.166).
}

Segundo Fleury (2004), a Constituição Federal de 1988 se traduz em um modelo de seguridade social que busca romper com a estrutura restrita, antes focalizada ao mercado de trabalho formal, ao passo que gera mecanismos mais solidários e redistributivos, tendo por base os princípios de justiça social, ao estender universalmente a cobertura. Nesse âmbito, Pereira salienta que o termo política social refere-se à política de ação que visa a atender 
necessidades sociais cuja resolução ultrapassa a iniciativa privada, individual e espontânea. Esta requer deliberada decisão coletiva regida por princípios de justiça social que, por sua vez, devem ser amparados por lei impessoais e objetivas garantidoras de direitos.

No que se refere à Previdência Social, Romero (2016) destaca que esta cobre uma série de contingências e riscos garantindo benefícios tais como: aposentadorias, pensões por morte, auxílios (por doença, por acidente e por reclusão), salário (família e maternidade) e serviços (perícia e reabilitação profissional). A Previdência Social é administrada pelo Instituto Nacional de Segurança Social (INSS) e se consolidou como o maior programa de transferência de renda do governo federal alcançando cerca de 32 milhões de beneficiários que recebem mais de $\mathrm{R} \$ 30$ bilhões por mês.

Certamente a política de previdência se constitui na principal fonte de renda para a população idosa. Todavia, Camarano e Fernandes (2016) destacam que enquanto as ações de saúde e de assistência social não requerem de seus usuários alguma contribuição monetária específica para a sua utilização, o mesmo não acontece com a Previdência Social. Esta requer custeio prévio, o que limita o acesso apenas ao contribuinte e a seus dependentes.

Já o Benefício de Prestação Continuada vinculado à Assistência Social é uma transferência de renda mensal, no valor de um salário mínimo, garantida pelo art. 203 da CF/1988 e regulamentada pelos arts. 20 e 21 da Lei Orgânica de Assistência Social. As transferências são independentes de contribuições prévias para o sistema de Seguridade Social e o benefício é destinado às pessoas idosas acima de 65 anos ou pessoas com deficiências incapacitantes para o trabalho, cuja renda familiar per capita seja inferior a um quarto do salário mínimo.

Os órgãos componentes do sistema de controle do BPC são o Instituto Nacional de Seguro Social (INSS), órgão operador; e o MDS, órgão regulador. Ou seja, embora a coordenação seja feita pelo MDS, a solicitação do benefício se dá em agências do INSS. O BPC é financiado com recursos da Seguridade Social alocados no Fundo Nacional de Assistência Social (Fnas). Segundo Berzins, Giacomin e Camarano (2016) em dezoito anos de BPC, observa-se um aumento de mais de quatrocentas vezes no número de concessões aos idosos. 
Com relação às aposentadorias, Camarano, Kanso e Fernandes (2016) observam que estas constituíam 36,8\% do total da renda dos idosos em 1983, e esta importância aumentou para 52,2\% em 2014. Já as pensões por morte, cuja participação era em torno de $33 \%$ entre 1983 e 1993 diminuiu para 27,7\% em 2014. As autoras revelam que a proporção de idosos que recebiam algum tipo de benefício previdenciário passou de 59,6\%, em 1983, para 74,9\% em 2014. Esse aumento beneficiou homens e mulheres, mas, relativamente falando, mais as mulheres. Em 2014, 75,2\% dos homens idosos e 74,7\% das mulheres eram beneficiários da Previdência Social.

Além de contribuir para a distribuição da renda, Castro (2011) revela que as políticas sociais de modo geral podem promover crescimento econômico, uma vez que grande parte dos gastos sociais do governo beneficiam as pessoas mais empobrecidas. Isso faz com que uma quantia significativa desse valor permaneça no país, tendo em vista que este estrato da sociedade é o que tem maior propensão a consumir produtos nacionais. Com isso, há um aumento na geração de emprego e renda, no crescimento do Produto Interno Bruto (PIB), bem como na renda das famílias.

Com a finalidade de verificar o impacto dos gastos sociais no crescimento do PIB, Castro (2011) mensurou que a cada $\mathrm{R} \$ 100,00$ gastos com políticas sociais, o PIB aumenta $R \$ 137,00$. E no que diz respeito às transferências da previdência social com aposentadoria, pensões e auxílios, foi mensurado pelo autor que a cada $\mathrm{R} \$ 100,00$ gastos, o PIB é aumentado em $R \$ 123,00$. Este forte impacto se dá, sobretudo frente à desigualdade de renda, na qual uma transferência de recursos, por mais neutra que seja, atua significativamente reduzindo a pobreza.

Essa observação foi feita também por Camarano e Fernandes (2016). As autoras mensuraram o impacto da renda da Seguridade Social no grau de pobreza dos domicílios brasileiros eliminando-a do cálculo da renda destes. Verificaram que a proporção de domicílios com idosos pobres em 2014 seria de 48,4\%, porém quando incluíram na análise o valor proveniente da Seguridade Social esse dado caiu para 3,9\%. Estes resultados atestam a importância que os benefícios da Seguridade Social têm desempenhado na redução da pobreza da população como um todo. 
Também Augusto e Ribeiro (2005) afirmam que o valor mínimo pago pelo benefício previdenciário - e nesse caso especialmente a aposentadoria rural - dinamiza a economia local dos pequenos municípios, sobretudo de regiões pobres, pois esta renda é gasta em sua maior parte nos comércios locais, proporcionando aumento do emprego, dos estabelecimentos, e maior movimentação financeira devido ao pagamento mensal do benefício. Os autores destacam ainda o forte impacto da Previdência Social na melhoria das condições de vida dos aposentados e de seus familiares.

Por fim, Camarano e Fernandes (2016) salientam que a renda da população idosa depende fortemente da renda da Previdência Social e que o sistema existente tem sido capaz de resolver de forma satisfatória a pobreza entre os idosos no país, beneficiando, também, os não idosos:

\footnotetext{
Assim sendo, pode-se dizer que a universalização da previdência cumpre uma função de proteção social moderna. Além disso, a política da previdência permite, no espaço privado familiar, uma revalorização das pessoas idosas, as quais, com a renda de aposentadoria, obtêm uma espécie de salvaguarda de subsistência familiar, invertendo o papel social de assistidos para assistentes, no contexto da estratégia de sobrevivência das famílias pobres (p.287).
}

Em síntese, a Previdência Social e o BPC cumprem um papel fundamental no âmbito da Seguridade Social contribuindo para a redistribuição de renda. Ao assegurarem condições mínimas de sobrevivência à população beneficiada estas políticas atuam sobretudo na redução da pobreza e da desigualdade social. A seguir, analisa-se o desempenho da Previdência Social e do BPC nos municípios do Corede Litoral.

\section{Universo Analítico: Conselho Regional de Desenvolvimento do Litoral/RS}

O Corede Litoral, foi criado em 1991 e atualmente é composto por 21 municípios: Arroio do Sal, Balneário Pinhal, Capão da Canoa, Capivari do Sul, Caraá, Cidreira, Dom Pedro de Alcântara, Imbé, Itati, Mampituba, Maquiné, Morrinhos do Sul, Mostardas, Osório, Palmares do Sul, Terra de Areia, Torres, Tramandaí, Três Cachoeiras, Três Forquilhas e Xangri-lá. 
Figura 1 - Municípios pertencentes ao Corede Litoral - RS

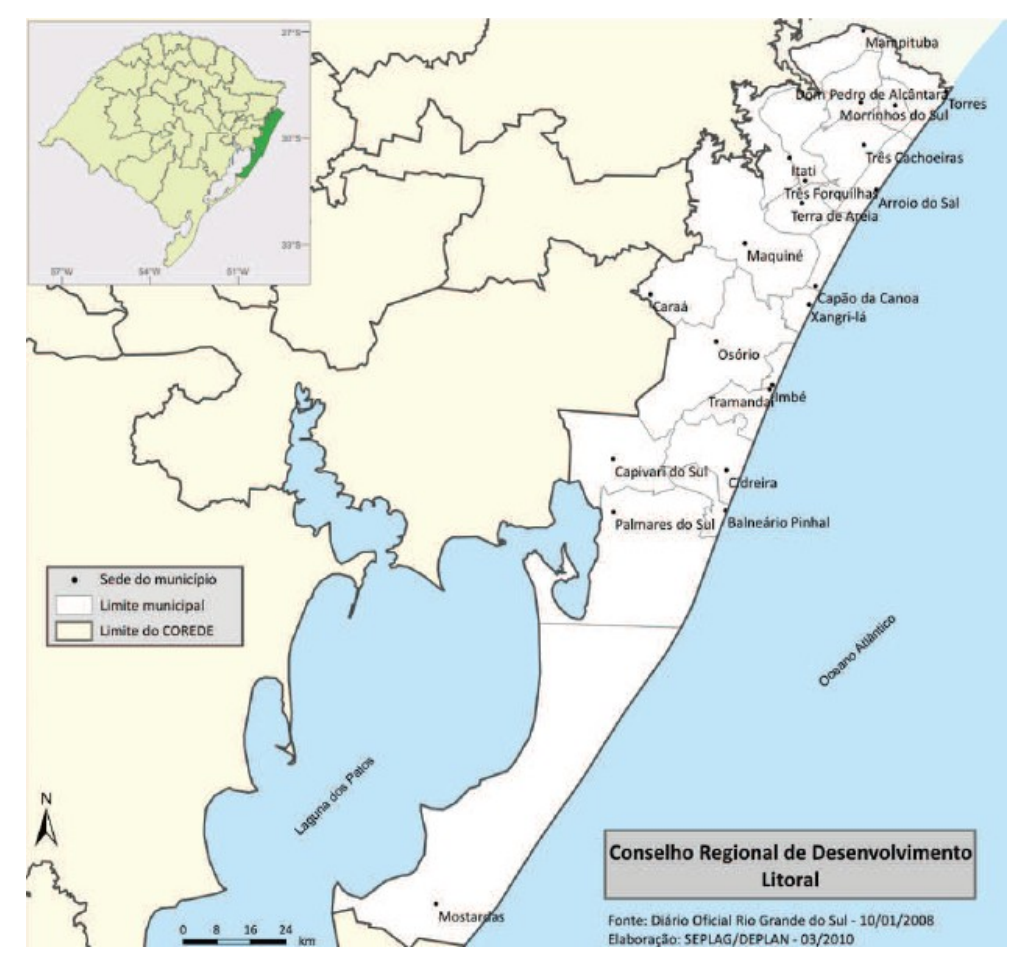

Fonte: Corede Litoral (2015).

Primeiramente são apresentadas informações referentes ao envelhecimento populacional dos municípios pertencentes ao Corede Litoral. Essas são fornecidas pelo Censo do IBGE de 2000 e 2010 e pelo Programa das Nações Unidas para o Desenvolvimento (PNUD). E na sequência observa-se os dados da Previdência Social e do BPC a fim de analisar o desempenho destas políticas sociais na região.

\subsection{Dinâmica Populacional no Corede Litoral}

Segundo a Fundação de Economia e Estatística, em 2016 o Corede Litoral possuía uma população de 334.107 habitantes. Os municípios mais populosos são Capão da Canoa, Tramandaí e Osório apresentando em torno de 40 mil habitantes. Em segundo plano, aparecem Torres, com 34.656 habitantes, e um grupo formado por Imbé, Cidreira, Xangri-lá, Mostardas, Palmares do Sul, Balneário Pinhal e Três Cachoeiras, com populações entre 10 e 
20 mil habitantes. Os demais municípios possuem populações abaixo de 10 mil habitantes. Esse Corede apresenta a particularidade de que os municípios localizados próximos ao litoral recebem um fluxo intenso de veranistas, chegando a cerca de 1.000 .000 habitantes entre os meses de dezembro a março (Corede Litoral, 2015).

No período de $2000-2010$, com um aumento de $22 \%$, o Corede Litoral foi a região que apresentou o maior crescimento populacional do estado do Rio Grande do Sul. E quando se analisa somente a população acima de 60 anos, verifica-se um aumento de $75 \%$, também superior a todos os demais Coredes, e à média nacional, que foi de $42 \%$ para o referido período. Conforme revela o último censo, há um total de 42.039 pessoas acima de 60 anos de idade residindo nos 21 municípios da região. Vale ressaltar que o Rio Grande do Sul possui a menor taxa de fecundidade entre os estados brasileiros e a quarta maior expectativa de vida do Brasil. A seguir o Gráfico 1 apresenta a população idosa residente nos municípios do Corede Litoral/RS:

Gráfico 1 - População idosa residente nos municípios do Corede Litoral/RS (2010)

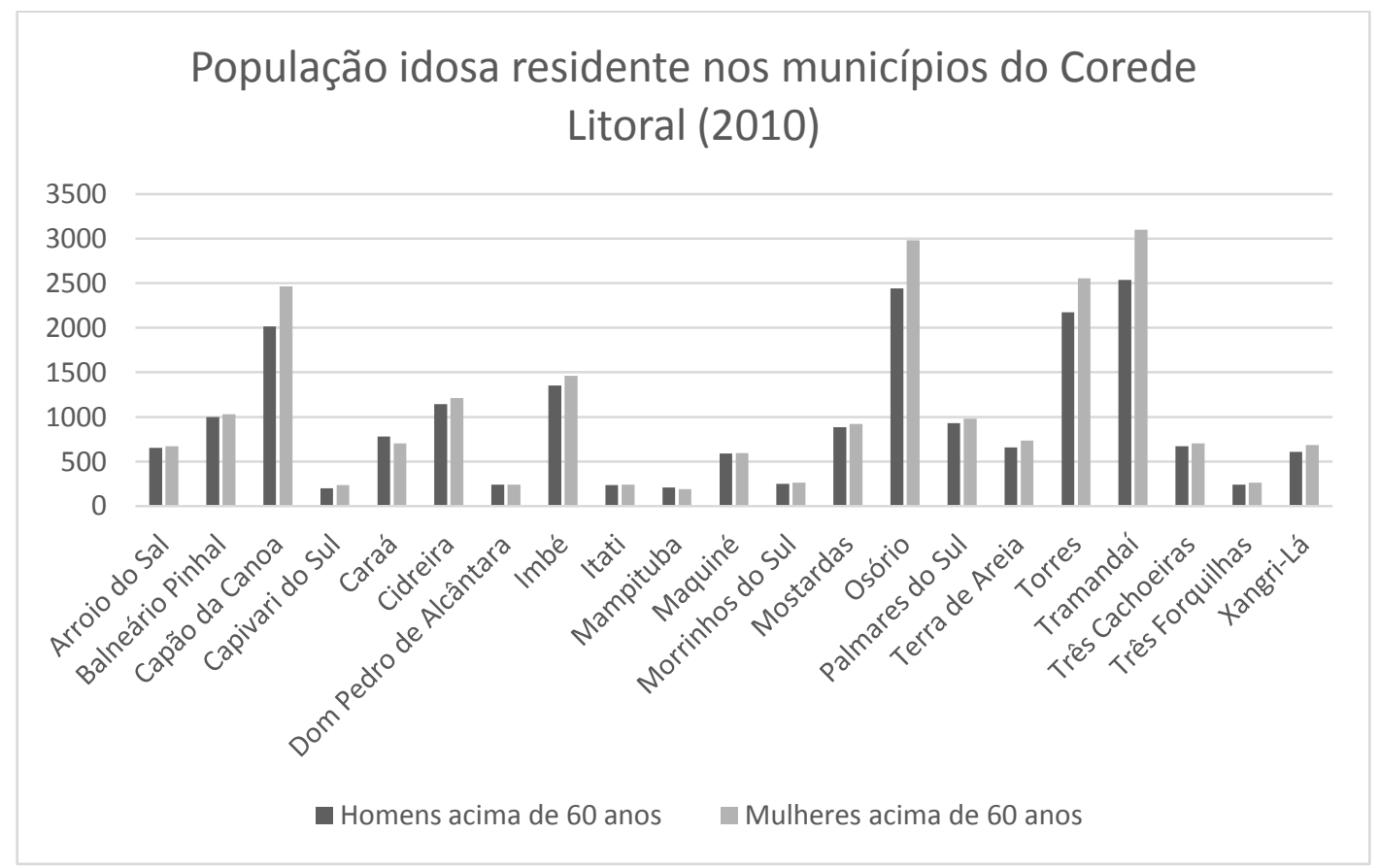

Fonte: IBGE, Elaboração própria. 
Conforme revela o Gráfico 1, dentre os municípios que apresentam a maior população idosa está Tramandaí com cerca de 5600 idosos, Osório com aproximadamente 5400, seguidos por Torres com 4729 e Capão da Canoa com 4475 idosos. Na maioria dos municípios há mais mulheres idosas dos que homens, convergindo com a tendência nacional, com exceção de Caraá e Mampituba. Estes são municípios rurais onde se verifica o fenômeno da masculinização do campo, também identificado por Froehlich et al. (2011) em um estudo efetuado em municípios do Rio Grande do Sul, e por Maciel (2013) na Associação dos Municípios da Região Carbonífera (AMREC)/SC.

Observando o Gráfico 2 é possível analisar os municípios que apresentam aumento da população idosa com base nos Censos de 2000 e 2010. Balneário Pinhal, Xangrilá, Imbé, Arroio do Sal, Cidreira, Capão da Canoa e Tramandaí respectivamente foram os municípios que mais atraíram idosos, haja vista que dobraram a população acima de 60 anos para o referido período. Por outro lado, Três Cachoeiras, Dom Pedro de Alcântara, Mostardas, Morrinhos do Sul, Mampituba, Maquiné, Três Forquilhas e Palmares do Sul foram os municípios que apresentaram menor crescimento, seguidos por Terra de Areia e Caraá que tiveram redução na população idosa de respectivamente $1 \%$ e $28 \%$.

\section{Gráfico 2 - Percentual da população idosa (2000/2010)}

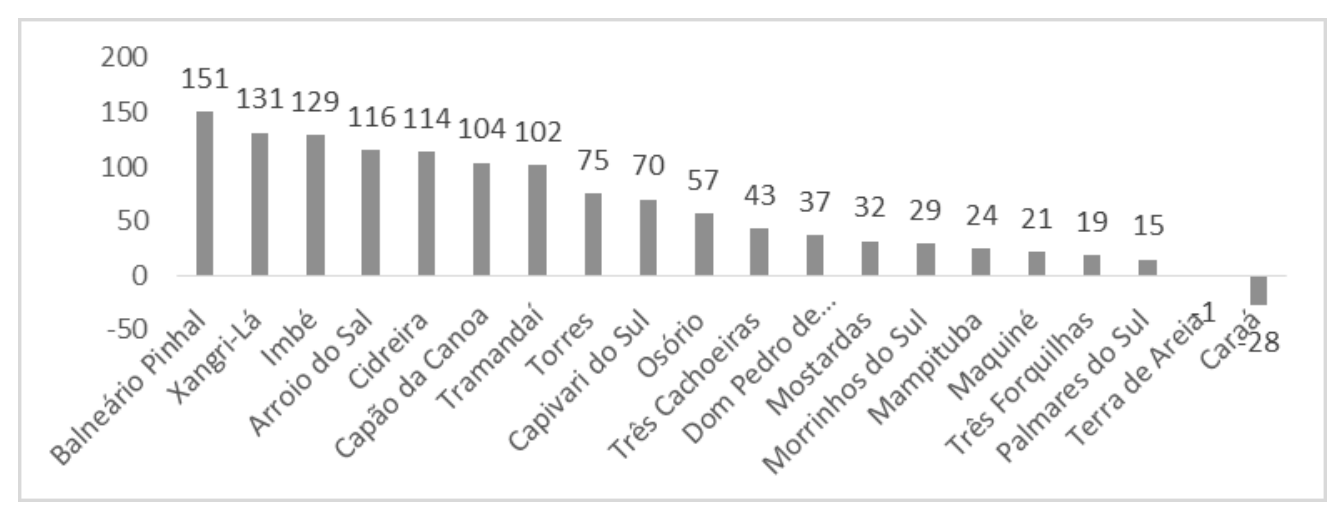

Fonte: IBGE, Elaboração própria.

Este contraponto se dá pelas especificidades de cada município: aqueles que apresentaram aumentos substanciais da população idosa são balneários que oferecem praias, lazer e, portanto, mais opções de turismo, tornando-se espaços atrativos para idosos 
que alcançaram a aposentadoria e buscam um lugar tranquilo para morar nesta fase da vida. Por outro lado, os municípios que apresentaram menor crescimento e até redução da população idosa partilham da semelhança de serem em sua maioria rurais.

Embora os balneários apresentem expressivos aumentos da população idosa, os municípios rurais destacam-se pelo intenso processo de envelhecimento, uma vez que grande parte dos seus habitantes são pessoas acima de 60 anos, a exemplo do município de Caraá, onde mais de $20 \%$ da sua população é idosa. A problemática do envelhecimento do campo não é algo presente somente nos municípios rurais pertencentes ao Corede Litoral/RS. Este mesmo fenômeno foi evidenciado por Bitencourt e Dalto (2015) na região da AMREC/SC onde os autores constataram não apenas o aumento da população idosa, mas também o êxodo rural de jovens. Este foi problematizado por Silvestro et al. (2001) e Stropasolas (2002) em outras regiões do Estado de Santa Catarina, e também por Coradini (2008) no Rio Grande do Sul.

A seguir, o Gráfico 3 apresenta a Taxa de Envelhecimento Humano para os municípios da região. De acordo com o PNUD, a Taxa de Envelhecimento Humano é calculada a partir da razão entre a população de 65 anos ou mais de idade e a população total multiplicado por 100.

Gráfico 3 - Taxa de Envelhecimento (2010)

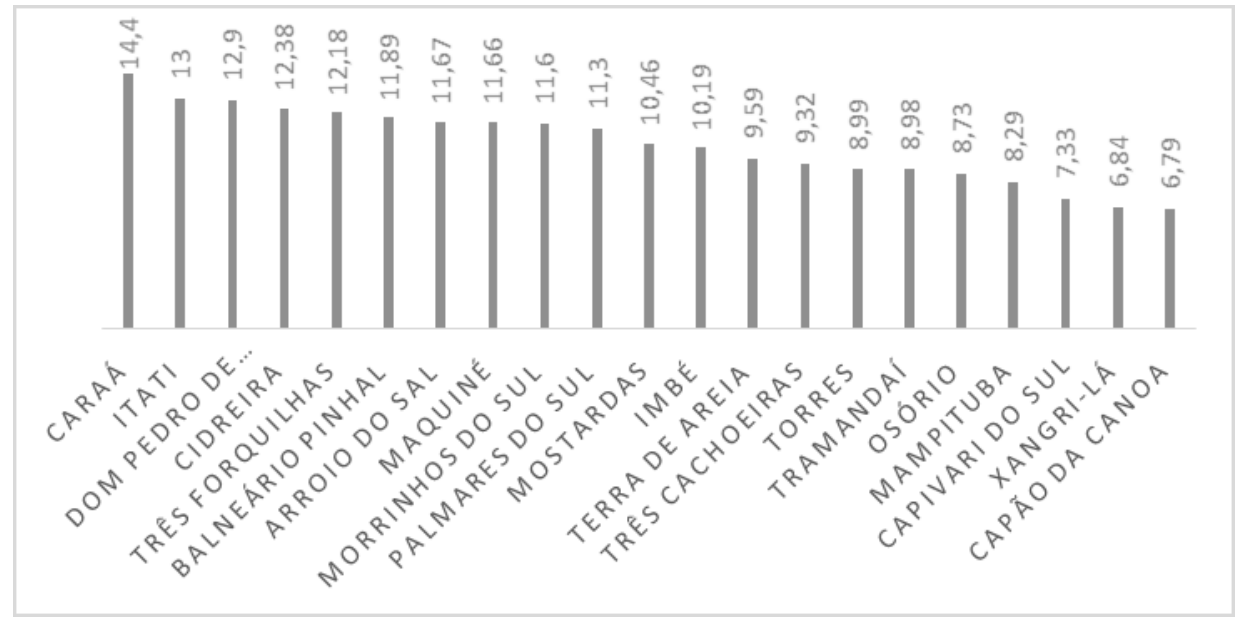

Fonte: PNUD, Elaboração própria

COLÓQUIO - Revista do Desenvolvimento Regional - Faccat - Taquara/RS - Edição Especial II SNDR, jan. 2019 
Esse dado corrobora com os dados dos Censos de 2000 e 2010, uma vez que os municípios rurais se destacam por apresentarem as mais altas taxas, a exemplo de Caraá com 14,4, seguido por Itati com 13 e Dom Pedro de Alcântara com 12,9. Após analisar os principais aspectos do envelhecimento populacional do Corede Litoral/RS, a seguir discute-se a inserção das rendas da Previdência Social e do Benefício de Prestação Continuada nos municípios da região.

4.2 Impactos da Previdência Social e do Benefício de Prestação Continuada no Corede Litoral

A fim de analisar o impacto da renda dos idosos na economia dos municípios pertencentes ao Corede Litoral, foram selecionadas as duas políticas sociais que se traduzem nas principais fontes de renda da população idosa: a Previdência Social e o Benefício de Prestação Continuada. Os dados foram coletados com base no ano de 2017. A partir do Sinconfi (Sistema de Informações Contábeis e Fiscais do Setor Público Brasileiro) também foram obtidas as receitas municipais para o mesmo período.

A seguir o Gráfico 4 apresenta o valor total dos benefícios previdenciários pagos por município em dezembro de 2017 incluindo: aposentadoria por idade, aposentadoria por invalidez, aposentadoria por tempo de contribuição, pensões por morte, auxílios, outros benefícios previdenciários.

\section{Gráfico 4 - Valor Total de Benefícios Previdenciários pagos em dezembro de 2017}

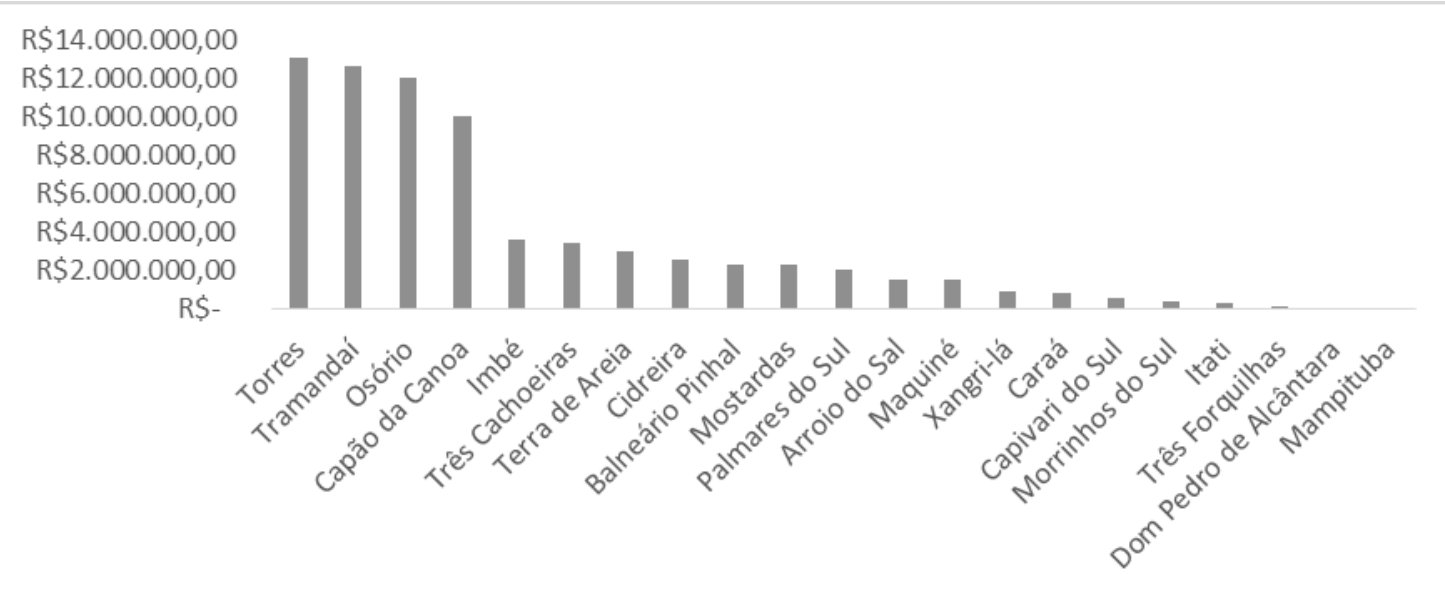

Fonte: Secretaria de Previdência Social, Elaboração Própria. 
Conforme demonstra o gráfico acima, Torres é o município da região que apresenta a maior renda proveniente da Previdência Social, chegando a aproximadamente $R \$ 13$ milhões somente em dezembro de 2017 - valor expressivo para um município cuja população é de aproximadamente $38 \mathrm{mil}$ habitantes. Na sequência estão os municípios de Tramandaí e Osório com o valor de aproximadamente $\mathrm{R} \$ 12$ milhões e Capão da Canoa com cerca de $\mathrm{R} \$ 10$ milhões. É interessante observar que mesmo não sendo o município com a maior população idosa da região, Torres se destaca por apresentar o maior número de benefícios da Previdência Social. Contudo, esse dado não revela a quantidade de beneficiados por município, pois um indivíduo pode acumular mais de um benefício - tal como aposentadoria e pensão.

A seguir, a partir dos dados coletados junto ao Ministério do Desenvolvimento Social (MDS), o Gráfico 5 mostra o valor do Benefício de Prestação Continuada pago por município em dezembro de 2017.

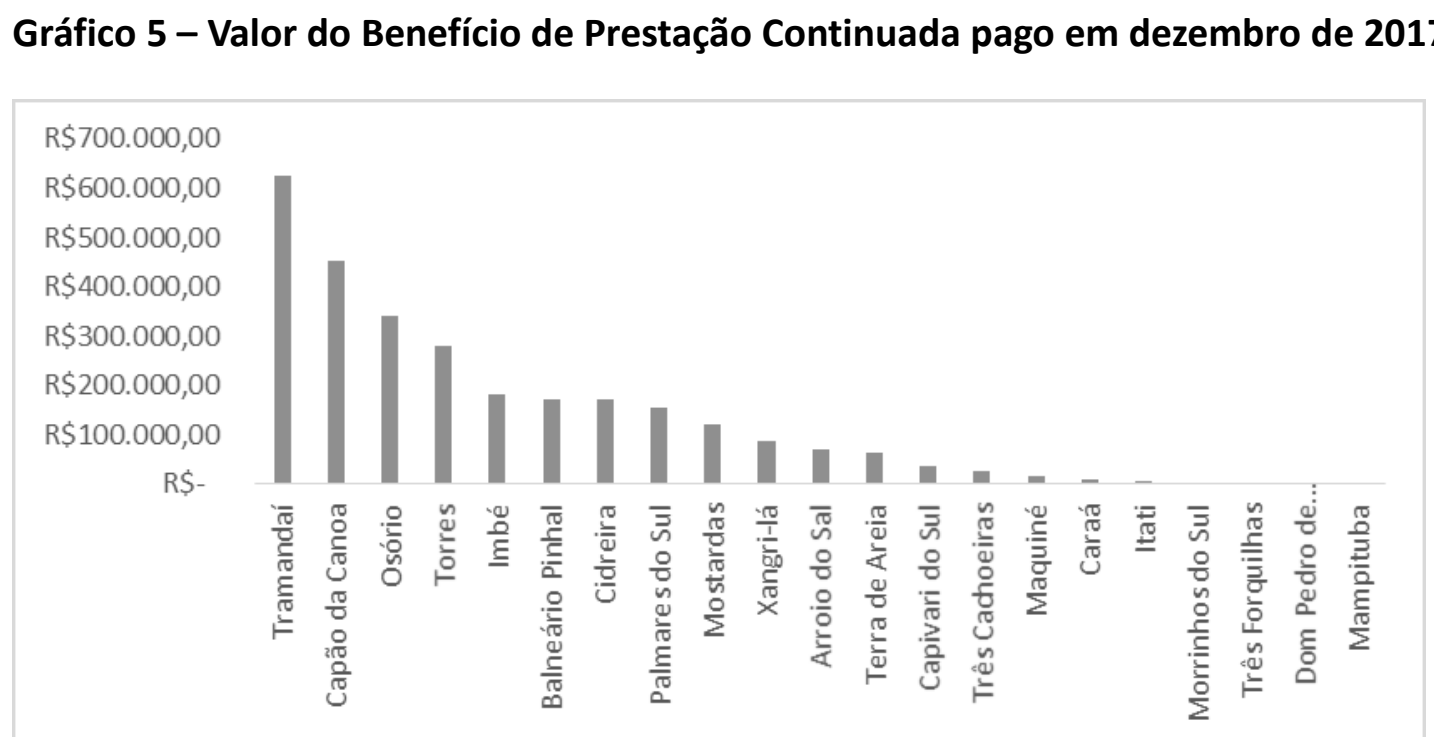

Fonte: MDS, Elaboração própria.

O Gráfico 5 revela que Tramandaí é o município da região com a maior renda proveniente do BPC; em dezembro de 2017 o valor chegou a aproximadamente $\mathrm{R} \$ 600$ mil, o equivalente a 670 benefícios com alcance em 12\% da população idosa residente em 
Tramandaí - lembrando que o valor de cada benefício corresponde a um salário mínimo. $\mathrm{Na}$ sequência encontra-se o município de Capão da Canoa com $\mathrm{R} \$ 452$ mil referente à 483 benefícios contemplando $11 \%$ de sua população idosa. Osório e Torres também se destacam com cerca de $\mathrm{R} \$ 342$ mil e $\mathrm{R} \$ 280$ mil respectivamente, porém nestes municípios o BPC alcança menos de $7 \%$ dos habitantes idosos.

Como o BPC é destinado aos idosos acima de 65 anos desprovidos de outra fonte regular de renda, esse dado revela que Tramandaí e Capão da Canoa são os municípios que contemplam a população idosa economicamente mais vulnerável da região. Por outro lado, nos municípios rurais o BPC tem baixa inserção: Itati, Morrinhos do Sul e Três Forquilhas apresentam juntos um total de 12 beneficiados; em Mampituba e Dom Pedro de Alcântara não há registro de idosos beneficiados em dezembro de 2017.

Isso se justifica pelo alcance da Previdência Social Rural (PSR) que contempla no campo mulheres acima de 55 anos e homens acima de 60 anos. No meio rural, para o segurado especial ter acesso à previdência não há necessidade de contribuição prévia, bastando comprovar o exercício da atividade agrícola, o que a torna uma política de distribuição de renda central. Certamente, se não houvesse a PSR o número de idosos economicamente vulneráveis no campo seria mais expressivo.

A fim de analisar o impacto destas rendas (Previdência Social + BCP) na economia do Corede Litoral, a seguir o Gráfico 6 apresenta o somatório de ambas junto à receita total de cada município. Esta contempla as receitas correntes e de capital envolvendo todos os tributos, taxas e contribuições municipais. 


\section{Gráfico 6 - Previdência Social + BPC x Receitas Municipais (2017)}

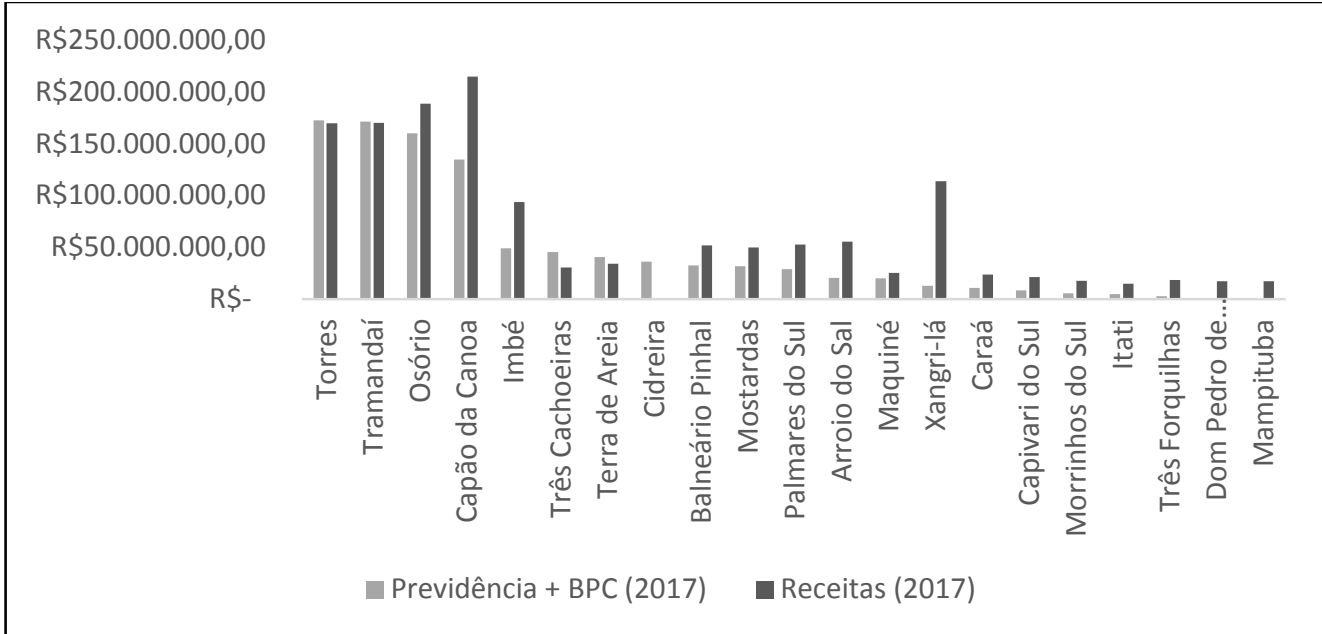

Fonte: Secretaria de Previdência Social, MDS, Sinconfi; Elaboração própria.

Conforme demonstra o gráfico acima, Capão da Canoa é o município da região que apresenta a maior receita proveniente de tributos, taxas e contribuições atingindo no ano de 2017 o valor total de $\mathrm{R} \$ 215$ milhões. Na sequência destacam-se Osório com cerca de $\mathrm{R} \$ 188$ milhões, Tramandaí e Torres com uma receita média de $\mathrm{R} \$ 170$ milhões. Na maioria dos municípios as receitas superam os valores provenientes da Previdência Social e do BPC, com exceção de Torres, Tramandaí, Três Cachoeiras e Terra de Areia. Nestes quatro a participação da renda dos idosos supera a receita orçamentária anual, o que significa dizer que boa parte da renda que gira nestes municípios advém da população idosa.

Estudos como de Guimarães e Santos (2008) convergem com esta análise, os autores pesquisaram o município de Ferros, em Minas Gerais e identificaram que a Previdência Social exerce importância predominante na economia local, uma vez que os valores pagos mensalmente superam as demais rendas locais. Além disso, eles acrescentam que o desenvolvimento econômico e social da região é fomentado pela renda dos aposentados e pensionistas da previdência, que garante inclusive a subsistência do comércio local.

Também Albuquerque, Lobo e Raymundo (1999) argumentam que a estabilidade econômica proporcionada pela Previdência Social assume uma dimensão social uma vez que contribui para o aumento das relações comerciais. Esses autores pontuam que os idosos 
aposentados representam um ingresso regular de renda que se traduz na compra de produtos alimentícios. Corroborando com estes autores, Augusto e Ribeiro (2005) afirmam que a renda mínima paga pelo benefício previdenciário dinamiza a economia local dos pequenos municípios, pois é gasta totalmente no comércio local, proporcionando aumento do emprego e consequentemente maior movimentação financeira.

Castro (2011), Camarano e Fernandes (2016) Augusto e Ribeiro (2005) demonstraram em suas pesquisas que por representar um ingresso regular de renda, a Previdência Social e o BPC desempenham papel fundamental não somente na condição de vida dos idosos e de seus familiares, mas contribuem para o desenvolvimento socioeconômico local. Logo, no Corede Litoral esta movimentação financeira mediada pela população idosa favorece o comércio, aumentando o emprego e a estabilidade econômica dos municípios. Como a maior parte desta renda é gasta em bens para própria subsistência, o impacto se dá frente à desigualdade de renda, na qual uma transferência de recursos, por mais neutra que seja, atua significativamente reduzindo a pobreza.

\section{Considerações finais}

Frente ao objetivo de investigar o processo de envelhecimento populacional nos municípios do Conselho Regional de Desenvolvimento (Corede) do Litoral/RS, constatou-se inicialmente que no período de 2000-2010 esta foi a região do estado com maior destaque no aumento populacional. Com relação à população acima de 60 anos, este aumento foi de 75\% superando as médias estadual e nacional. Todavia este cenário revela as especificidades de um processo de envelhecimento distinto. Por um lado, tem-se o aumento da população idosa nos balneários proveniente de pessoas que residiam na região metropolitana do estado, e após a aposentadoria buscam um lugar tranquilo que propicie lazer e maior qualidade de vida. Por outro lado, os municípios rurais destacam-se pelo intenso processo de envelhecimento daqueles que permanecem no campo.

Com relação à Previdência Social, mesmo não sendo o município com a maior população idosa da região, Torres se destaca por apresentar o maior número de benefícios e, 
portanto, a maior renda proveniente desta política, chegando a aproximadamente $\mathrm{R} \$ 13$ milhões em 2017. Já os municípios de Tramandaí e Capão da Canoa chamam atenção por possuírem o maior número de beneficiários pelo BPC com alcance em $12 \%$ dos idosos, o que os caracterizam por contemplarem a população idosa economicamente mais vulnerável da região. Por outro lado, nos municípios rurais o BPC tem baixa inserção, possivelmente pelo desempenho da Previdência Social Rural.

E por fim, com base na análise das receitas orçamentárias, foi possível identificar que nos municípios de Torres, Tramandaí, Três Cachoeiras e Terra de Areia as receitas provenientes da Previdência Social e do BPC superam a renda orçamentária anual, o que significa dizer que boa tarde da renda que gira nestes municípios advém da população idosa. E frente ao envelhecimento populacional evidente na região, a tendência é que nos demais municípios a renda da população idosa também exerça papel significativo no desenvolvimento socioeconômico, haja vista o montante que gira mensalmente advindos da Previdência Social e do BPC.

Este trabalho revela, portanto, que a Previdência Social e o BPC asseguram aos idosos residentes no Corede Litoral a garantia de uma renda regular que Ihes confere o mínimo de segurança e dignidade, uma vez que boa parte deste valor - se não integralmente - é utilizada na própria subsistência. Mais do que mera provisão financeira por parte do Estado, estas políticas sociais geram impactos profundos nos cenários em que atuam. Seja nos balneários, no campo ou nos municípios economicamente mais vulneráveis, a transferência destes recursos atua contribuindo significativamente para o desenvolvimento socioeconômico da região.

\section{Referências}

ALBUQUERQUE, Francisco José B.; LOBO, Alexandre Lucena; RAYMUNDO, Jorge da Silva. Análise das repercussões psicossociais decorrentes da concessão de benefícios rurais. Psicologia: Reflexão e Crítica, v.12, n.2, p. 503-519, 1999.

AUGUSTO, Hélder dos Anjos; RIBEIRO, Eduardo Magalhães. O envelhecimento e as aposentadorias no ambiente rural: um enfoque bibliográfico. Organizações Rurais \& Agroindustriais, v. 7, n. 2, p. 199-208, mai-ago, 2005. 
BRASIL. Constituição da República Federativa do Brasil. Brasília, DF: Senado, 1988.

BERZINS, Marília Anselmo Viana da Silva; GIACOMIN, Karla Cristina; CAMARANO, Ana Amélia. Assistência Social na Política Nacional do Idoso. In: ALCÂNTARA, Alexandre de Oliveira; CAMARANO, Ana Amélia; GIACOMIN, Karla Cristina. Política Nacional do Idoso: velhas e novas questões. Rio de Janeiro: Ipea, 2016. p. 107-133.

BITENCOURT, Rossandra Oliveira Maciel de; DALTO, Fabiano Abranches Silva. A contribuição da Previdência Social Rural para a redução da desigualdade de renda. Revista de Desenvolvimento Econômico, Salvador, v. 17, n. 2, p.892-914, dez. 2015.

CAMARANO, Ana Amélia et al. Como vive o idoso brasileiro? In: CAMARANO, Ana. Amélia. (Org.). Os novos idosos brasileiros: muito além dos 60? Rio de Janeiro: Ipea, 2004. p. 25-73.

CAMARANO, Ana Amélia; FERNANDES, Daniele. A Previdência Social Brasileira. In: ALCÂNTARA, Alexandre de Oliveira; CAMARANO, Ana Amélia; GIACOMIN, Karla Cristina. Política Nacional do Idoso: velhas e novas questões. Rio de Janeiro: Ipea, 2016. p. 265-294.

CAMARANO, Ana Amélia; KANSO, Solange; FERNANDES, Daniele. Brasil envelhece antes e pós-CNI. In: ALCÂNTARA, Alexandre de Oliveira; CAMARANO, Ana Amélia; GIACOMIN, Karla Cristina. Política Nacional do Idoso: velhas e novas questões. Rio de Janeiro: Ipea, 2016. p. 63-103.

CASTRO, Jorge Abrahão. Política Social no Brasil: marco conceitual e análise da ampliação do escopo, escala e gasto público. Revista brasileira de monitoramento e avaliação. Brasília, v1. p.66-65, Jan-jun/2011.

COREDE Litoral. Perfil Socioeconômico do Corede Litoral. Governo do Estado do Rio Grande do Sul, Secretaria do Planejamento, Mobilidade e Desenvolvimento Regional, 2015.

CORADINI, Lucas. Autonomia e Projetos Profissionais das Jovens na Agricultura Familiar do Rio Grande do Sul. In: BRASIL, Presidência da República. 3 Prêmio Construindo a Igualdade de Gênero - Redações e artigos científicos vencedores. Brasília: Secretaria Especial de Políticas para as Mulheres. 2008.p.176-188.

FLEURY, Silvia. A Seguridade Social inconclusa. In: INSTITUTO DE ESTUDO SOCIOECONÔMICOS. A Era FHC e o governo Lula. Brasília: INESC, p.110-119, 2004.

FROEHLICH, José Marcos et al. Êxodo seletivo, masculinização e envelhecimento da população rural na região central do RS. Ciência Rural, Santa Maria, v. 41, n. 9, set. p. 16741680. 2011. 
FUNDAÇÃO DE ECONOMIA E ESTATÍSTICA. Perfil Socioeconômico Coredes/RS, 2015. Disponível em: <www.fee.rs.gov.br/perfil-socioeconomico/coredes/> Acesso em 03.ago.2018.

GUIMARÃES, Juarez Nonato; SANTOS, Carlos Alberto da Penha. Participação da Previdência Social como Fonte de Riqueza no Município de Ferros/MG. Revista de Administração da Unimep, v 6, n.1, p. 81-100, jan-abr, 2008.

HODGSON, Geoffrey. What are institutions? Journal of Economic Issues, v. 40, n.1, pp.1-25, 2006.

IBGE. Banco de Dados Agregados. Censo 2010.

MACIEL, Rossandra Oliveira. A internalização da Previdência Social Rural em municípios pertencentes à região da AMREC. 2015. 95 f. Dissertação (Mestrado) - Curso de Políticas Públicas, Universidade Federal do Paraná, Curitiba, 2013.

MINISTÉRIO DO DESENVOLVIMENTO SOCIAL. Quantitativo de benefícios e recursos investidos por unidade da federação de pagamento no período de 1996 a 2018. Disponível em: <www.mds.gov.br/relcrys/bpc/download_beneficiarios_bpc.htm>. Acesso em 15.ago.2018.

MOTTA, Alda Britto da. As dimensões de gênero e classe social na análise do envelhecimento. Cadernos Pagu, Campinas, n. 13, p.191-221, 1999.

ORGANIZAÇÃO INTERNACIONAL DO TRABALHO. OIT no Brasil: trabalho decente para uma vida digna. 2012. Disponível em: < http://www.ilo.org/wcmsp5/groups/public/---americas/--ro-lima/---ilo-brasilia/documents/publication/wcms_234393.pdf> Acesso em 30 ago 2018.

UNITED NATIONS. World Population Ageing. New York, 2015. 164p.

PEREIRA, Potyara Amazoneida Pereira. Política Social: temas e questões. São Paulo: Cortez, 2011. 214p.

PROGRAMA DA NAÇÕES UNIDAS PARA O DESENVOLVIMENTO. Atlas do Desenvolvimento Humano, 2013.

RIO GRANDE DO SUL. Lei n. 10.283, de 17 de outubro de 1994. Dispõe sobre a criação dos Conselhos Regionais de Desenvolvimento - CRDs, Porto Alegre, 1994.

ROMERO, Vilson Antônio. 93 anos de Previdência no Brasil. Artigos da Associação Nacional dos Auditores Fiscais da Receita Federal, 2016. Disponível em: <http://www.anfip.org.br/informacoes/artigos/93-anos-de-Previdencia-no-Brasil-VilsonAntonio-Romero_22-01-2016>. Acesso em 25 out.2016. 
SECRETARIA DE PREVIDÊNCIA. Estatísticas Municipais 2017. Disponível em: <www.previdencia.gov.br/dados-abertos/estatisticas-municipais-2017/>. Acesso em 15 ago.2018.

SILVESTRO, Milton Luiz et al. Os impasses sociais da sucessão hereditária na agricultura familiar. Florianópolis: EPAGRI; Brasília: Ministério do Desenvolvimento Agrário, 2001.

SIQUEIRA, R. L et al. A velhice: algumas considerações teóricas e conceituais. Ciência e Saúde Coletiva, Rio de Janeiro, v. 7, n. 4, p. 899-906, 2002.

SISTEMA DE INFORMAÇÕES CONTÁBEIS E FISCAIS DO SETOR PÚBLICO BRASILEIRO. ContaS anuais: exercício 2017. Disponível em: <siconfi.tesouro.gov.br/siconfi/index.jsf>. Acesso em 15 ago.2018.

SKOCPOL, Theda. Bringing the State Back In. Cambridge: Cambridge University Press, 1985.

STROPASOLAS, Valmir Luiz. O mundo rural no horizonte dos jovens. Florianópolis: Ed. da Universidade do Extremo Sul Catarinense, 2006. 346 p. 